\title{
Do trágico ao obsceno: o Amphitruo de plauto
}

\author{
From tragic to obscene: the Amphitruo of Plautus \\ Marcos Tindo \\ Universidade Federal do Rio Grande do Norte - Rio Grande do Norte - Brasil
}

\begin{abstract}
Resumo: Este breve texto analisa as ambiguidades presentes na peça Amphitruo, do autor romano Plauto, ao conceber um enredo apto a um tratamento cômico apesar de baseado do mito da concepção de Hércules, o qual já havia anteriormente sido recontada em tragédias. Abordam-se aqui as transformações que o mito sofre nas mãos do comediógrafo, as quais se concentram principalmente no nível da personagem. Com base na narrativa e nas falas das personagens, demonstra-se como o autor alcançou o objetivo de adaptar a fábula a um roteiro cômico por meio duma mudança na apresentação das personagens, especialmente duas das principais: nomeadamente, Júpiter e Alcmena, que foram degradadas dos seus lugares originários de figuras de respeito, por meio de reiteradas associações obscenas.
\end{abstract}

Palavras-chave: Teatro romano; Obscenidade; Tragédia; Comédia; Mito

\begin{abstract}
This brief text analyzes the ambiguities present in the play Amphitruo, by the Roman author Plauto, in conceiveing a plot apt to a comic treatment, although based on the myth of the conception of Hercules, which had previously been retold in tragedies. The transformations that the myth undergoes in the hands of the comedian, which are concentrated mainly in the level of the character, are approached here. Based on the narrative and the lines of the characters, it is demonstrated how the author achieved the goal of adapting the fable to a comic script through a change in the presentation the characters, especially two of the main ones: namely, Jupiter and Alcmena, who were degraded from their original places of figures of respect, by means of repeated obscene associations.
\end{abstract}

Keywords: Roman theater; Obscenity; Tragedy; Comedy; Myth

\section{Introdução}

Amphitruo $^{1}$ é uma comédia escrita em verso em uma forma de latim pré-clássico que foi datada como composta no segundo século antes da Era Comum. Apesar da ausência quase total de qualquer indicador histórico dentro da narrativa (FONTAINE, 2010, p. 188), essa datação deve-se ao fato de a peça ter sido catalogada dentre as vinte que eram consensualmente ditas como plautinas na Antiguidade (NORWOOD, 1932, p. 16). Amphitruo, entretanto, destaca-se dessas vinte e uma peças pelo tema mitológico (em todas as demais a ação tem um fundo mais mundano) e pelas personagens divinas (nas outras comédias, as personagens são todas mortais), além do fato de ser a única que se inicia por uma afirmação da própria heterogeneidade em relação

\footnotetext{
O título da peça será aqui grafado sempre no original latino, para evitar confundir-se com o nome do protagonista epônimo, que será aqui referido sempre como Anfitrião.
}

às convenções genéricas do seu tempo: logo no prólogo, afirma-se que não será uma comédia como as outras, mas uma "tragicomédia" (GONÇALVES, 2015, p. 53). É uma das comédias de duplos de Plauto, em cujas tramas personagens de aparência idêntica são a causa de confusão e engano.

Uma das razões de esta peça diferir das suas congêneres, porém, é o fato de a geminação entre as personagens ser parte de um engodo propositado desde o início. Essa distinção no enredo dá ocasião a distinções mais profundas no texto, de forma que a peça explora, mais aprofundadamente do que qualquer outra de que se tenha notícia (seja dentre as obras plautinas restantes ou perdidas, seja na comédia romana em geral), a duplicidade e a ambiguidade como motivo (CHRISTENSON, 2000, p. 13).

Em Amphitruo, o autor escolheu inserir elementos que lhe possibilitassem que a duplicidade desempenhasse o papel preponderante. O que se apresenta primordial- 
mente quando, ao misturar elementos que não deveriam estar juntos, Plauto usa personagens de origem trágica, sob uma luz pouco lisonjeira. Este trabalho pretende demonstrar que grande parte da comicidade (tanto nas falas como na estrutura do enredo) se deve à forma como são retratadas duas das personagens principais.

\section{A ambiguidade}

A ambiguidade, porém, inicia-se desde a escolha do tema. Diferentemente das demais peças de duplos plautinas, não há aqui uma semelhança natural que é usada como artifício por homens, mas uma farsa arquitetada e engendrada por deuses. Isso se dá por razão de a peça não se passar numa Hélade mais ou menos contemporânea ao autor, mas num passado mítico. É verdade que, na escritura de Plauto, a Grécia (que lhe fornecia os modelos nos quais se inspirava para elaborar as suas versões) vinha retratada como pouco mais que um pano de fundo etéreo, uma terra imaginária onde as restrições morais romanas podiam ceder lugar à licenciosidade, e a rejeição a essas mores enfatizava esse distanciamento ainda mais com um certo tom de discurso moralizante (MOORE, 1998, p. 199). Isso the dava espaço para dizer coisas que, se a peça se passasse em Roma, seriam talvez indizíveis. Em Amphitruo, esse distanciamento amplia-se ainda mais, devido ao fato de o elemento mitológico - presente noutras obras do mesmo autor somente em citações e reminiscências das personagens - aqui ganha corpo e toma o proscênio. A peça constrói-se, portanto, com elementos da lenda e da tragédia, que são distorcidos e explorados pela via cômica (DUPONT, 1998, p. 4).

Esse fator torna-se mais notório quando se observa que as fábulas da mitologia são, via de regra, bastante ausentes na representação cômica do período clássico (FRAENKEL, 2007, p. 8), tanto nos fragmentos como nas passagens mais longas que chegaram até aos dias de hoje. Deve-se ter em mente, porém, que o religioso não está de todo ausente da comédia romana. Pelo contrário: a religião pode ser encontrada na comédia mais frequentemente do que as sensibilidades modernas ocidentais esperariam ver em tal gênero. Apesar disso, menções religiosas são menos frequentes na obra de Terêncio que na de Plauto, que é geralmente entendido como sendo o menos intelectualmente sofisticado dos dois. Em Plauto, o papel da religião normalmente assume a forma de alusões a divindades e ritos religiosos (DUCKWORTH, 1994, p.295), com a aparição ocasional de uma figura divina, como prologista nos chamados "prólogos de divindade", de acordo com a classificação de Raffaelli (2009, p. 15). Prólogos plautinos nessa categoria geralmente, porém, não são falados por uma das principais divindades, mas sim por deuses de escalões menores.
Mas Amphitruo vai além disso: aqui, a ambientação é feita a partir de um episódio mitológico, e dois dos protagonistas são deuses de primeira classe. Um deles, inclusive, é o maior dos deuses: Júpiter, um personagem que o público contemporâneo não estava acostumado a ver retratado em drama. Em parte alguma dos textos que nos chegaram da Antiguidade consta que Júpiter tenha sido personagem falante numa peça (SCHUTTER, 1952, p. 3) e - a julgar pelo trecho que se refere à surpresa da plateia com esse fato - este deve ter sido um dos raros casos (ou o único) em que isso se passou. Este talvez seja o ponto mais peculiar desta peça muito peculiar.

O enredo recria os eventos que levarão ao nascimento de Hércules (embora o texto não mencione a criança por nome, e o público contemporâneo romano só se tenha dado conta desse fato a partir do seu próprio conhecimento prévio da lenda). Ainda assim, é uma comédia, afinal de contas, e por isso narra esse conto de natividade sob a forma de uma caricatura cômica. E mais: essa trama faz deuses e generais interagir com escravos, e ainda traz um dos doze olímpicos disfarçado de escravo em pleno palco. E, pelo que sobreviveu de drama da Antiguidade, grega ou romana, esta também parece ter sido a exceção e não a regra.

Plauto também toma liberdades quanto à urdidura do mito, ao acrescentar-lhe elementos anteriormente inexistentes, como o escravo Sósia. Este serve somente para prover mais uma duplicação, a do deus Mercúrio, que se disfarça dele (DUPONT, 1998, p. 5). Isso é por causa da natureza do tema e das compatibilidades naturais de certos tipos de personagens com certos gêneros. A partir das convenções do cânone clássico, que foram organizadas e catalogadas por Aristóteles (mas segundo princípios que certamente o precedem), é evidente que havia uma relação muito próxima entre gênero, tema e personagens (MANUWALD, 2011, p. 145-146). A Comédia, de acordo com a norma, deve ser apenas sobre as pessoas de classe baixa, feiura, feitos e mal-feitos dos sem importância. E, de fato, a própria inclusão entre o elenco de personagens (e como uma das personagens principais!) de um escravo nato, por exemplo, tornaria a matéria inadequada para um tratamento trágico. Deuses, reis e generais, por outro lado, reservam-se para a Tragédia.

Outra dessas subversões da convenção acontece porque, ao optar por escrever uma comédia com um enredo envolvendo personagens e um episódio mais familiar à tragédia, o escritor criou um obstáculo para si mesmo: a história não era risível. Um obstáculo que ele escolheu vencer por meio dum expediente: a profanação. Plauto tenta então neutralizar a gravidade intrínseca do mito, evitando que o seu tratamento cômico da fábula degenerasse para uma espécie de tragédia intercalada com gracejos. 
A forma de profanação escolhida para a tarefa era dúplice: a adição de um segundo elenco de personagens que não fazia parte do mito original e que se encaixa mais facilmente numa comédia: assim Sósia e Mercúrio (que nunca é visto aqui sem o seu disfarce, o que faz que ele, portanto, consista em pouco mais que um escravo, embora divino) foram trazidos para a história. Restava então diminuir ao nível peculiar à Comédia as personagens com origem na Tragédia, em especial Júpiter e Alcmena.

\section{Júpiter e Alcmena}

A razão pela qual essas duas personagens não seriam cômicas é bastante simples: Mercúrio e Sósia seriam suficientemente ridículos como os escravos que eram, e Anfitrião, por ser enganado e depois humilhado no palco, tornar-se-ia risível em tempo. A fábula (e a moral religiosa), no entanto, não dariam espaço para Júpiter ser descrito como outra coisa senão o todo-poderoso deus vitorioso que sempre foi. E Alcmena não poderia ser transformada na figura de repressão sexual e social que era reservada para a matrona, em peças plautinas, que é ridicularizada pelas personagens mais simpáticas (SLATER, 1985, p. 157): seria impossível para ela ser a desmancha-prazeres, porque ela própria era o prazer. $\mathrm{O}$ comediógrafo encontra a solução ampliando e explorando esse aspecto à exaustão: faz estes dois serem mais obscenos do que o resto, destarte profanando-os.

Mas isso não foi conseguido da maneira mais fácil, que teria sido simplesmente adicionar indecência verbal gratuita aos diálogos. Em vez disso, o enredo usa a obscenidade como um meio de profanação das personagens em sua essência. Na verdade, os casos de obscenidade verbal direta em todas as comédias de Plauto são menos numerosos e menos indecentes do que seria de esperar (se isso se deve à censura estatal ou à vontade espontânea do autor a abster-se, tal questão não é ponto pacífico) e, na maior parte, consiste em insinuação, envolta pela ambiguidade, e tornada inofensiva pelo humor que gera no fim da fala (DUCKWORTH, 1994, p. 295, 303): os textos plautinos contêm pouco ou nenhum calão, o que surpreende quando comparado com a Comédia ática, por exemplo, ou até mesmo com sátiras e invectivas romanas escritas em períodos posteriores. O que significa que a sua obscenidade, embora não seja frequente, não se destina a ser subversiva, nem a oporse ao que era então considerado como a norma sexual (RICHLIN, 2005, p.29). Dentro dos limites corretos, a obscenidade poderia ser admissível na cultura romana de seu tempo. Segundo Duckworth (1994, p. 295), muito do que alguns modernos consideram chocante e anormal teria parecido um assunto perfeitamente apropriado ao ridículo e ao riso, para um espectador romano. As reações deles não eram prejudicadas por séculos de cristianismo.

O que não significa, contudo, que Amphitruo seja uma peça totalmente decorosa, mas simplesmente que, a fim de alcançar a risibilidade que pretendia, o autor encontrou outras maneiras de des-higienizar o tema: a obscenidade não era gratuita, mas sim elaboradamente tecida na trama (RICHLIN, 2005, p. 34) e utilizada como instrumento de degradação, de forma semelhante àquela como funciona em Bacchides, quando Nicóbulo e Filoxeno cedem às irmãs gêmeas. Em Amphitruo, o autor escolheu ligar a obscenidade, praticamente na sua totalidade, precisamente às personagens que, de outra maneira, seriam as menos suscetíveis a serem ridicularizadas: Júpiter e Alcmena. O principal deus do panteão teve de ser alienado do seu caráter sagrado, de modo a tornar-se personagem sem profundidade, cuja única preocupação parece ser seu desejo por Alcmena. Feito assim de ridículo, também o ato de inseminação à futura mãe do seu filho semideus é ridicularizado. A insistência na lascívia da relação sexual dos dois sobrecarrega a peça (até mesmo as cenas em que nenhum dos dois aparece), de tal forma que, ao longo de todo o prólogo e da maior parte da primeira cena, praticamente a única informação real que temos sobre o enredo principal é que Júpiter está fazendo sexo (SEGAL, 1987, p. 178).

Já Alcmena é associada com algumas das características peculiares a uma personagem do tipo meretriz (v. 287). Para piorar a situação, a mulher no palco (se ela foi ou não interpretada por um ator masculino não é relevante aqui) é explicitamente mencionada pelos outros três protagonistas como visivelmente grávida, o que, na ausência de didascálias autorais, é provavelmente uma indicação de que haveria uma barriga falsa usada pela pessoa que a interpretasse. O estágio avançado da gravidez de Alcmena que está sendo mostrado no palco não tem precedentes, pelo que se pode saber do resto do teatro romano. Além de ser um pouco obsceno em si mesmo (também porque naquele tempo uma certa conexão costumava ser feita entre deficiências físicas e morais), era também um lembrete constante do caso de amor dela aos olhos do público, a quem o adultério era uma ofensa, se cometido por uma mulher, embora compreensível se por um homem (CHRISTENSON, 2000, p.225). Tal insistência na gravidez torna-se mais uma acusação de lascívia. $\mathrm{Na}$ verdade, o próprio fato de que ela revela sentir atração ou até mesmo amor por um homem, assim como a sua reafirmação do prazer marital, fazem dela a única esposa em todo o corpus plautino a demonstrar desejo pelo marido; de fato, expressar isso não seria exatamente $\mathrm{O}$ que era esperado ser ouvido do caráter de uma senhora casada. Esse tipo de desejo ativo parece ser inconveniente para uma senhora (CHRISTENSON, 2000, p. 231) 
e já a qualificaria para ser vista como indigna: as convenções morais do tempo limitavam a representação cômica das relações amorosas das mulheres a ser uma hetaira cortejada, se consensual, ou vítima de violação, se não (GARCÍA-HERNÁNDEZ, 2001, p. 131, 133). E os apartes intrusivos dos escravos durante os diálogos com Júpiter e Anfitrião reiteram a grotesca associação dessas duas categorias muito diferentes na concepção romana das mulheres (GARCÍA-HERNÁNDEZ, 2001, p.134) e parecem não servir para nada além de abaixar a personagem e para acentuar essa ambiguidade perante o público.

O encontro da esposa de Anfitrião com Júpiter é retratado nesta peça como ato de mero adultério ocasionado por luxúria. Plauto imprime na conduta do deus a ideia de clandestinidade por meio duma escolha lexical que sempre transmite esse significado: clam, clanculum, clandestinus, celare (GARCÍA-HERNÁNDEZ, 2001, p. 135), o que lhe dá ares de jovem rebelde agindo às escondidas. Isso, porém, não significa que o mito era, em si, engraçado desde sempre. Enquanto os detalhes duma história em que a sedução joviana se dá por metamorfose podem sugerir jocosidade, esta escapada de Júpiter não parece ter sido intrinsecamente mais engraçada do que qualquer outra, antes de ser adaptada para a Comédia. Embora os detalhes da história possam ser sugestivos de humor, se friamente analisados (COSTA, 1965, p. 91), a impregnação de uma mulher mortal é vista noutros relatos como uma exibição da proeza masculina do deus (KILINSKI, 1998, p. 29) e um ato de amor que dignifica, e não vilifica, a figura do deus e a da mulher a quem é concedida essa honra. A sexualidade, apesar de já presente no mito original, é ainda latente e seria apenas aqui exagerada a ponto de se transformar em obscenidade mera e vulgar. A impropriedade da história só surge quando é usada uma abordagem trocista na narração, da mesma maneira como o enobrecimento surgiria se fosse contada em tom heróico. De forma semelhante, mutatis mutandis, os cristãos hoje em dia contam a história da natividade de Jesus de forma glorificada, quando ela também poderia muito bem ser contada comicamente (sem mudar um único elemento), como o conto de uma mulher casada que é engravidada por alguém que não é seu marido, com o consentimento deste, e depois se recusa a ter relações sexuais com o cônjuge para não se macular. Vê-se, portanto, que a linha entre a noite santa e a noite profana pode ser mais tênue do que parece à primeira vista. Talvez essa mudança de ponto de vista que muda toda a percepção do enredo fosse a ideia por detrás da observação de Mercúrio no prólogo, de que ele poderia mudar toda a peça, transformando-a de tragédia em comédia, sem alterar uma só palavra (v. 55).

Destarte, as personagens de Júpiter e Alcmena tornam-se mais engraçadas ao serem alvos desse expe- diente por se manipular a expectativa do público para que opere como o gatilho do riso, porque há comicidade quando as coisas saem ao contrário das expectativas: certa situação ou declaração é a esperada, mas algo diferente, por vezes incongruente com ela, ou que dela não decorreria naturalmente, ou mesmo que seria impossível ocorrer no curso natural dos eventos desenvolve-se no seu lugar (DUCKWORTH, 1994, p.318). O retrato incongruente das personagens, em comparação com o que o público teria considerado normal, é o que torna o papel deles divertido (CHALMERS, 1965, p. 21). Naturalmente, a incongruência é um mecanismo omnipresente em todas as comédias plautinas, mas Plauto faz uma utilização muito mais intensa nesta peça em particular.

Deve-se ressaltar que, mesmo que esta peça seja baseada num modelo grego precedente (não há consenso sobre qual peça, qual autor, ou mesmo se houve ou não um original grego), a atitude romana em relação à divindade, e especialmente a uma falta de decoro voltada à divindade, quando se tratava da performance teatral, era provavelmente mais sensível do que a dos seus predecessores atenienses (MOORE, 1998, p. 109). Assim, esta versão latina teria tido, de longe, mais impacto sobre o público que a assistiu pela primeira vez. Embora a cultura grega pareça ter outrora sido mais leniente a respeito de rir do sagrado, no momento em que os romanos vieram, a atitude já mudara. Em Atenas, num tempo em que a divisão entre sagrado e profano pode ter sido menos clara, podia-se zombar de figuras divinas, uma concessão da qual testemunham As Rãs de Aristófanes. Mas talvez este não seja o melhor exemplo, porque este caso pode ter sido mais aceitável por motivo de o deus ridicularizado ter sido Dionísio, a quem o riso era um meio sagrado de expressão válido, ao contrário dos demais olímpicos (GILHUS, 1997, p. 33, 39). Em qualquer caso, certa mudança nessa disposição poderia já estar em curso nesse momento. Afinal de contas, uma geração depois que essa peça foi encenada pela primeira vez, a zombaria não seria considerada aceitável aos olhos de Aristóteles, que desaprovava da inclinação do riso a ultrapassar limites assim como o seu rechaço ao deleite em indecências (GILHUS, 1997, p. 43). Esse ponto de vista, e não o mais concessivo, foi o herdado pelos romanos, uma norma apenas relaxada durante as festividades em que os ludi ocorriam (SEGAL, 1987, p.9-14). Entretanto, sempre se mantinha uma certa reverência para com os deuses, razão pela qual personagens plautinos - mesmo aqueles em Amphitruo - reconhecem a importância dos deuses e de os propiciar: em nenhum momento Plauto contradiz ou mina a instituição religiosa, mesmo quando ele mostra o comportamento dos deuses sob uma luz menos lisonjeira, neste caso excecional (DUCKWORTH, 1994, p.298). Esse equilíbrio, porém, é difícil de sustentar. 
Júpiter e Alcmena ilustram melhor do que qualquer outro personagem a dificuldade que o autor criou para si mesmo ao optar por escrever uma comédia com um enredo envolvendo personagens e um episódio mais familiar a uma tragédia: a história não era risível. As intervenções constantes de Mercúrio e Sósia, presumivelmente, tentam neutralizar a seriedade intrínseca dela, insistindo no aspecto ridículo da peça.

Porém, enquanto Júpiter é capaz de, pelo menos, encarnar algumas personagens de estoque plautinas, como o jovem apaixonado ou o senhor zangado, o discurso de Alcmena não é engraçado. No que está no controle dela, ela é de fato optima e proba. O que ela não pode controlar, no entanto, é de uma natureza completamente diferente: uma vez que o enredo principal herdado do mito impede o dramaturgo de torná-la ridícula no que ela é, parece haver uma tentativa deliberada de obscurecer a sua inclinação trágica, por fazer a sua imagem oscilar ambiguamente entre esposa e puta, e assim agravar ainda mais o mundo de pernas para o ar que o enredo forja. O efeito geral é o de maximizar a sexualidade da farsa (CHRISTENSON, 2000, p. 194). Desde o prólogo (vv. 107-108), e repetidas vezes ao longo da peça (vv. 498, 980-981, 1135-1136), esta honrada esposa de general e futura mãe de semideus é degradantemente mencionada como "mulher emprestada". Desde a primeira cena, tão logo Sósia menciona homens luxuriosos e prostitutas Mercúrio imediatamente relaciona-os ao apetite de Júpiter por Alcmena.

A ambivalência de compor a esposa fiel e a prostituta em um único personagem não passaria despercebida pelo público contemporâneo de Plauto. Nas primeiras cenas onde ela interage com seus maridos real e falso, os requerimentos de amor que ela exprime seriam algo reservado para a prostituta, na Comédia Nova (CHRISTENSON, 2000, p. 231). É relevante, a este respeito, a escolha da terminologia afetiva nas falas das personagens, que indica a fatalidade e a destrutividade potencial da paixão (PADUANO, 1953, p. 66).

A própria Alcmena, no entanto, não está consciente de sua própria ambiguidade e, portanto, continua proclamando a sua própria justiça (v. 645). O retrato que suas palavras pintam é o da matrona romana preocupada apenas com o marido, em primeiro lugar, com a família e com a nação. Quando confrontada pelo marido com uma acusação de infidelidade (vv. 839-842), a lista de valores femininos que ela testemunha lembra os epítetos mais frequentes gravados nas lápides de mulheres romanas (CHRYSTAL, 2013, p. 13). Essa lista de virtudes, no entanto, não é gratuita e responde às suspeitas levantadas por Anfitrião, e corresponde ao seu comportamento consciente na peça: seu auto-retrato moral é real e integrado ao enredo (GARCÍA-HERNÁNDEZ, 2001, p. 116).
Esse resquício de obséquio solene certamente se deve ao fato de se ter a personagem originado no tratamento trágico, especialmente no que é dado a ela por Eurípides (AUGELLO, 1972, p.126), com o qual sabemos que a audiência do tempo de Plauto teria familiaridade. É, porém, uma figura distorcida, com uma barriga enorme, que o público sabe que carrega o filho do amante, quem está dando discursos morais com certas conotações filosóficas (DUTSCH, 2008, p. 155) sobre a fidelidade e a conformidade com a norma. Essa figura e essa situação cômica contrastam com o tom trágico (PHILLIPS, 185 , p. 125). Alcmena é realmente a expressão duma tragédia que se transformou em comédia sem mudar uma palavra. Plauto só quer fazer rir a multidão e o seu público tem pouca tolerância com filosofia, razão pela qual Júpiter, mais tarde, parodia as palavras de Alcmena e, no fim, as destitui de qualquer gravidade (vv. 937-40.) (CHRISTENSON, 2000, p. 251).

Mesmo as suas frases de pietas convencional parecem estar imbuídas de conotação sexual quando colocadas no contexto da farsa em que ela está inserida: toda a primeira parte do seu monódio sobre virtus e a sua ideia de aprazer aos deuses (v. 635) ganha novos matizes de significado aos ouvidos do público, que está a par do que se passa. A sua fala gira em torno da ideia de voluptas, que poderia muito bem ser entendida como o gozo espiritual (GLARE, 1968, p. 2102). A mesma palavra, no entanto, também transmite o significado do prazer físico, muitas vezes também com as conotações sexuais a palavra 'prazer' tem em português (ADAMS, 1982, p. 197). Ela alega ser morigera, palavra que se refere ao cumprimento dos deveres domésticos romanos tradicionais (GUNDERSON, 2015, p. 190), mas também evoca a sujeição sexual (ADAMS, 1982, p. 164). É provavelmente intencional que ecoe a mesma palavra no prólogo de Mercúrio (vv. 113-114) referindo-se às escapadas sexuais de Júpiter, e a insinuação sexual é reforçada quando lembramos que o elemento sexual já havia sido deixado claro na afeição de Alcmena pelo seu marido, ao dizer adeus ao falso Anfitrião (PHILLIPS, 1865 , p. 125) em uma cena anterior.

Como as palavras de Alcmena têm uma aparência geral de seriedade, esta cena é o que pode ter levado alguns comentadores a concluir que ela se tratasse uma personagem totalmente trágica fora de contexto, o que justificaria a denominação de "tragicomédia" que o autor traz no prólogo da peça. A pluralidade de Alcmena, no entanto, reside no fato de que, ao contrário das outras protagonistas que encontram sua duplicidade em outras personagens, ela encarna o seu próprio duplo Alcmena não apenas não tem um duplo, mas também reúne dois papéis em um só: o de matrona e o de meretriz. Ela encarna o seu próprio duplo (PETRONE, 2009, p. 178). Essa contradição nela, da qual o próprio Plauto pode ter- 
nos dado uma pista: quando ele faz Mercúrio dizer que a peça será uma tragicomédia, isso não significa que esse termo tenha a conotação que hoje em dia lhe damos: a razão que ele oferece para tal categoria é que ele poderia transformá-la, de comédia em tragédia, sem alterar qualquer palavra (vv. 54-59). É precisamente isso que faz Alcmena engraçada: o fato de que as falas dela não pertencem no mundo onde ela está. Ela é cômica por falar tragicamente e não viver de acordo com as suas palavras: o humor, especialmente do tipo envolvendo brincadeiras sexuais, é duas vezes mais engraçado quando vem de uma fonte inesperada ou em um contexto inesperado (PHILLIPS, 1985, p. 126).

\section{Conclusão}

Neste trabalho, procurou-se mostrar os expedientes dos quais se serviu o comediógrafo romano para transformar o material dum mito originalmente trágico num enredo de comédia. Evidenciou-se, com isso, que a maioria deles se deu no nível da personagem, com a inclusão de um grupo ausente das representações trágicas e épicas anteriores, e, principalmente, com a abordagem ambígua em relação a dois dos protagonistas, Júpiter e Alcmena, que, de outra forma seriam pouco propensos a gerar riso, e que tiveram, por isso, a sua imagem dessecrada com o efeito de os tornar mais aptos a serem ridicularizados. Pretendeu-se demonstrar, com referências às falas e ao enredo, que o principal meio de dessecração utilizado pelo autor foi a associação da obscenidade exclusivamente a esses personagens.

\section{Referências}

ADAMS, J. N. The Latin sexual vocabulary. London: Duckworth, 1982.

AUGELlO, Giuseppe. Plauto: le commedie, v. 1. Turim: Unione Tipografico Editrice, 1972.

CHALMERS, Walter R. Plautus and his audience. In: DOREY, T. A.; DUDLEY, D. R. Roman drama. London: Routledge \& Keagan Paul, 1965.

CHRISTENSON, David M. (Ed. e comp.). Plautus: Amphitruo. Cambrígia: Cambridge University Press, 2000.

CHRYSTAL, Paul. Women in Ancient Rome. Amberley: Stroud, 2013.

COSTA, C. D. N. The Amphitryo theme. In: DOREY, T. A.; DUDLEY, D. R. Roman drama. Londres: Routledge \& Keagan Paul, 1965.

DUCKWORTH, George E. The nature of Roman Comedy: a study in popular entertainment. 2. ed. Londres: Bristol Classical Press, 1994.

DUPONT, Florence. Signification théâtrale du double dans l'Amphitryon de Plaute. In: Vita Latina, Montpellier, n. 150, p. 2-12, 1998.
DUTSCH, Dorota. The beginnings: philosophy in Roman literature before 155 b.C. In: GARANI, M.; KONSTANS, D. (Ed.). The philosophizing muse: the influence of Greek philosophy on Roman poetry. Col. Pierides. Newcastle: Cambridge Scholars, 2014.

FRAENKEL, Eduard. Plautine elements in Plautus. Tradução inglesa de Tomas Drevikosky e Frances Muecke. Oxônia: Oxford University Press, 2007. (Original alemão: Plautinisches im Plautus).

GARCÍA-HERNÁNDEZ, Benjamín. Gemelos y sosias: la comedia de doble en Plauto, Shakespeare y Molière. Madrid: Ediciones Clásicas, 2001.

GLARE, P.G.W. (Ed.). Oxford Latin dictionary. Oxônia: Oxford University Press, 1968. Vol. 2.

GONÇALVES, Rodrigo Tadeu. Performative Plautus: sophistics, metaphysics and translation. Newcastle: Cambridge Scholars, 2015.

GILHUS, Ingvild Sælid. Laughing gods, weeping virgins: laughter in the history of religion. Londres: Routledge, 1997.

GUNDERSON, Erik. Laughing awry: Plautus and tragicomedy. Oxônia: Oxford University Press, 2015.

FONTAINE, Michael. Funny words in Plautine comedy. Oxônia: Oxford University Press, 2010.

KILINSKI II, Karl. Greek masculine prowess in the manifestations of Zeus. In: KEUREN, Frances Van. Myth, sexuality and power: images of Jupiter in Western art. Lovaina a Nova: Publications d'Histoire de l'Art e d'Archéologie de l'Université Catholique de Louvain, 1998.

MANUWALD, Gesine. Roman republican theatre. Cambrígia: Cambridge University Press, 2011.

MOORE, Timothy J. The theater of Plautus: playing to the audience. Austin: University of Texas Press, 1998.

NORWOOD, Gilbert. Plautus and Terence. Londres: Longman, Green \& Co, 1932.

PADUANO, Guido (Ed. e comp.). Identità e verità. In: Plauto. Anfitrione. Milão: Rizzoli, 1953.

PETRONE, Gianna. Quando le muse parlavano latino. Bolonha: Pàtron, 2009.

PHILLIPS, Jane E. Alcumena in the Amphitruo of Plautus: a pregnant lady joke. In: The classical journal, Classical Association of the Middle West and South (CAMWS), v. 80, n. 2, p. 121-126, 1985.

RAFFAELLI, Renato. Esercizi Plautini. Urbino: Quattroventi, 2009.

RICHLIN, Amy. Rome and the mysterious Orient: three plays by Plautus. Berkeley: University of California Press, 2005.

SCHUTTER, Klaas Herman. Comoediae Plautinae. Groninga: Dewaal, 1952.

SEGAL, Erich. Roman laughter: the comedy of Plautus. Nova Iorque: Oxford University Press, 1987.

SLATER, Niall W. Plautus in performance. Guilford: Princeton University Press, 1985.

Recebido: $17 / 12 / 16$

Aprovado: 02/04/17

Contato: mtindo@live.com 